\title{
Politiek van ons allemaal: reactie op de Kamerbrief van minister Ollongren over vrouwen in het openbaar bestuur*
}

\author{
Liza Mügge \& Zahra Runderkamp ${ }^{* *}$
}

\section{Inleiding}

Het vieren van honderd jaar vrouwenkiesrecht is een uitstekende aanleiding om het debat over de positie van vrouwen in de politiek en het openbaar bestuur anno 2019 nieuw leven in te blazen. Er valt veel te bespreken: wat valt er eigenlijk te vieren? Hoever zijn we al gekomen? En vooral: hoe nu verder? Minister van Binnenlandse Zaken Kajsa Ollongren geeft het startsein voor antwoorden op deze vragen in haar vlammende Kamerbrief Beleidsreactie rondetafelgesprek vrouwen in het openbaar bestuur van 2 juli 2019. In wat volgt zullen wij op deze brief reageren vanuit onze positie als wetenschappers. Ons doel is om het debat over de positie van vrouwen in de politiek te voeden met inzichten uit internationaal wetenschappelijk onderzoek.

Een van de maatregelen die minister Ollongren in de Kamerbrief initieert, is onderzoek naar succesfactoren en leerervaringen in andere landen. In dat verband schreven wij het essay 'De tweede sekse in politiek en openbaar bestuur: verklaringen en oplossingen voor de ondervertegenwoordiging van vrouwen' (Mügge \& Runderkamp, 2019). Dit artikel bouwt voort op dat essay. De centrale vraag van het essay is: welke factoren en interventies dragen bij aan gelijkheid tussen mannen en vrouwen in de politiek? Het startpunt van ons betoog in het essay 'De tweede sekse in politiek en openbaar bestuur' is het belang van gendergelijkheid. Daarna beschrijven we de barrières die vertegenwoordiging van vrouwen belemmeren. Vervolgens bespreken we factoren die de instroom, doorstroom en het behouden van vrouwen in de politiek en het openbaar bestuur stimuleren. We onderscheiden verschillende fasen van vertegenwoordiging voor meerdere groepen: aspiranten, kandidaten en gekozen/benoemde politici (Norris, 1996).

Net zoals in de Kamerbrief bespreken we eerst de trends en cijfers en vervolgens gaan we in op de maatregelen die Ollongren noemt: (1) inclusieve selectie en

* Dit essay is een bewerkte en ingekorte versie van 'De tweede sekse in politiek en openbaar bestuur: verklaringen en oplossingen voor de ondervertegenwoordiging van vrouwen' en een uitkomst van het Vidi-project van Liza Mugge, gefinancierd door de Nederlandse Organisatie voor Wetenschappelijk Onderzoek (NWO), projectnummer 016.Vidi.175.355. We danken ook het Ministerie van Binnenlandse Zaken. Het essay is te vinden via https:// kennisopenbaarbestuur.nl/rapporten-publicaties/op-weg-naar-een-beteremv-balans-in-politieken-bestuur/

** Dr. Liza Mügge is universitair hoofddocent politicologie aan de Universiteit van Amsterdam. Zahra Runderkamp is promovenda politicologie aan de Universiteit van Amsterdam. 
selectieprocedures, (2) actief uitnodigen en werven van kandidaten, en (3) goede toerusting in het politieke ambt.

\section{Trends: het glas is halfvol}

Minister Ollongren noemt in haar Kamerbrief een aantal cijfers: zij ziet over de afgelopen honderd jaar een gestage toename van vrouwen in de politiek. De minister heeft sinds haar aantreden vele vrouwelijke burgemeesters benoemd, en ook bij het Rijk kunnen we spreken van een toename van het aantal vrouwen. Maar, erkent de minister, het gaat traag en de toename vlakt af. Inderdaad is het glas halfvol. Zo wacht Nederland nog altijd op de eerste vrouwelijke minister-president. Ceylon, het huidige Sri Lanka, benoemde in 1960 al een vrouwelijke minister-president, en India in 1966. ${ }^{1}$ Het is niet erg waarschijnlijk dat er in Nederland in de komende jaren wel een vrouwelijke minister-president komt. Dit komt niet in de laatste plaats omdat vrouwen op de kandidatenlijsten van onze politieke partijen vaak op de tweede plek staan. Vrouwen zijn in dat opzicht letterlijk de tweede sekse in de politiek. Van de 28 partijen die in 2017 deelnamen aan de Tweede Kamerverkiezingen werden 25 partijen geleid door een man. ${ }^{2}$ Nog veelzeggender: Nederland staat op dit moment ${ }^{3}$ op de wereldranglijst van de InterParliamentary Union wat betreft het percentage vrouwen in nationale parlementen op nummer 42, onder Guyana en Zimbabwe (positie 40 en 41) en boven Kameroen (positie 43). ${ }^{4}$ Dat er actie nodig is om de positie van vrouwen in de politiek te verbeteren, is overduidelijk. Maar hoe?

\section{Inclusieve selectie en selectieprocedures: doorbreken van de geheime tuin}

Als eerste maatregel heeft de minister aandacht voor het belang van een inclusieve selectiefase. Een directe actie is de aanpassing van de selectieprocedures voor de commissaris van de Koning en burgemeestersbenoemingen. Het is nijpend dat Jetta Klijnsma op dit moment de enige vrouw van de twaalf commissarissen van de Koning is en slecht 21 procent van de burgemeesters vrouw is. De minister geeft hiermee het goede voorbeeld in de selecties waar zij direct invloed op heeft.

Daarnaast pleit Ollongren voor een evenwichtige samenstelling van selectie- en vertrouwenscommissies. We weten uit onderzoek dat dit belangrijk is. In de politicologie wordt rekrutering van kandidaten een 'geheime tuin' genoemd. De informele en voor niet-ingewijden onzichtbare aspecten van rekrutering lopen via bestaande netwerken - veelal gedomineerd door witte mannen (Bjarnegård \& Kenny, 2015). Training en begeleiding om dit proces te verbeteren zijn dus essentieel. We weten - overigens niet alleen uit de politiek - dat mensen graag kiezen voor kandidaten die op henzelf lijken.

Een recente Amerikaanse studie laat bijvoorbeeld zien dat rekrutering niet divers is. Slechts een klein aandeel op elkaar lijkende (lees: witte) vrouwen wordt verkozen. Zo bleken verkozen vrouwelijke politici opvallend hoog te scoren op 'ijverigheid'5 en 'extraversie'. De onderzoekers vergeleken namelijk de zogenaamde 'Big 
Five' van persoonlijkheidskenmerken: extraversie, vriendelijkheid, emotionele stabiliteit, ijverigheid en openheid. Zij speculeren dat vrouwen die verkozen worden zich extra gekwalificeerd moeten voelen om zich verkiesbaar te stellen. Extraversie is onmisbaar om mannelijke netwerken te doorbreken (Dynes e.a., 2019).

Om een meer diverse groep vrouwen te bereiken moeten de ingesleten ideeën en onduidelijke criteria die worden gehanteerd voor een 'goede' politicus worden herzien. Deze criteria zijn gebaseerd op een geschiedenis van vertegenwoordiging door (hoofdzakelijk) mannen (Murray, 2015). Dat is een gemiste kans om verschillende redenen. Gelijke vertegenwoordiging van zo veel mogelijk verschillende mannen en vrouwen is niet alleen een kwestie van sociale rechtvaardigheid. Politieke gelijkheid is een voorwaarde in elke democratie. Studies naar de vertegenwoordiging van historisch ondervertegenwoordigde groepen zoals vrouwen, etnische minderheden en LGBTQ bevestigen dat diversiteit een positief effect heeft op het functioneren van de democratie, sociale cohesie, vertrouwen in de politiek en de acceptatie van verkiezingsuitslagen, en negatieve heersende normen en stereotypen bijstelt (Ruedin, 2013; Reynolds, 2013). Bovendien gaat van een evenwichtig samengesteld parlement het signaal uit dat politiek een gedeelde verantwoordelijkheid is. Ten slotte levert het de samenleving nieuwe rolmodellen.

Bovenal is meer onderzoek nodig om beter te begrijpen wat voor historisch ondervertegenwoordigde groepen werkt en waarom. Wij vonden tijdens het schrijven van ons essay opvallend weinig materiaal over Nederland en de positie van vrouwen in de Nederlandse politiek. In andere landen is er, zowel op nationaal als internationaal vergelijkend niveau, meer onderzoek voorhanden. Het is aannemelijk dat een aantal basismechanismen van in- en uitsluiting in verschillende landen vergelijkbaar is met Nederland. Oplossingen in andere landen om gendergelijkheid in de politiek te vergroten kunnen daarom inspireren. Het is voor de toekomst van belang deze hypothese(n) ook te testen en meer inzicht te krijgen in de specifieke situatie in Nederland. Wij breken graag een lans voor de wetenschap om het debat over dit onderwerp verder te voeden met wetenschappelijke inzichten en wetenschappelijke bewijzen van effectiviteit.

\section{Actief uitnodigen en werven van kandidaten}

Een volgend speerpunt van de minister is actief uitnodigen en werven van vrouwelijke kandidaten. Mannen zijn oververtegenwoordigd in nagenoeg alle machtsposities in de politiek en het openbaar bestuur. Het is belangrijk dat de poule van mogelijke vrouwelijke kandidaten flink wordt uitgebreid. Essentieel bij de werving van nieuwe kandidaten is het stimuleren van interesse en ambitie in politiek. Rolmodellen spelen hierin een belangrijke rol. Uit Amerikaans onderzoek blijkt dat zichtbaarheid van vrouwelijke politici in de media positieve invloed heeft op de mate waarin jonge vrouwen aangeven zelf politiek actief te willen worden (Campbell \& Wolbrecht, 2006). Het onderliggende mechanisme is dat jonge vrouwen door zichtbare, in de media geportretteerde vrouwelijke politici meer over politiek gaan praten in hun sociale circuits en zo geëngageerd raken. Een jaar na deze 
publicatie lieten dezelfde auteurs zien dat dit effect zich ook in Europese landen voordoet (Wolbrecht \& Campbell, 2007). Het is zeker mogelijk ook op dit onderwerp extra maatregelen te nemen, die zich in het bijzonder op meisjes en jonge vrouwen richten.

Politieke partijen zullen, als ze diverser gaan rekruteren, hulp nodig hebben van het maatschappelijk middenveld dat (politiek achtergestelde) groepen op dit moment vertegenwoordigt. Politieke partijen in Nederland kregen in de jaren tachtig overheidssubsidies die specifiek gericht waren op het opzetten van programma's om (onder andere) meer vrouwen te betrekken, maar deze subsidies zijn inmiddels afgeschaft. Bestaande of recent opgerichte netwerken binnen partijen voor vrouwen of burgers met een migratieachtergrond blijken eveneens effectief om homogene rekruteringsnetwerken te doorbreken. Zij activeren kandidaten, maar kunnen hen ook aanbevelen, lobbyen en/of zichtbaar maken en hun kandidaatschap ondersteunen. In het verleden is binnen de Partij van de Arbeid (PvdA) bijvoorbeeld het Multi Etnisch Vrouwen Netwerk zeer succesvol gebleken Mügge \& Damstra, 2013). Geen partij heeft meer vrouwen met een migratieachtergrond op de lijst gehad dan de PvdA (Mügge, 2016). Mogelijke subsidiëring van dergelijke netwerken zou binnen het voorgestelde beleid van de minister passen. Ten slotte zijn niet aan een partij gebonden initiatieven van belang. Vrouwen kunnen al tijdens hun studie worden geactiveerd en ondersteund door trainingen (Mügge, 2014). Organisaties zoals Stem op een Vrouw en ProDemos werken hier al in verschillende vormen aan (Cursus Politiek actief, z.d.).

Maar de bal mag niet alleen bij de vrouwen liggen. Een doorgeslagen focus op de ambitie van vrouwen veronderstelt dat ondervertegenwoordiging een probleem is dat vrouwen zelf creëren. Het risico is dat hierdoor structurele uitsluitingsmechanismen niet worden aangepakt, zoals rekruteringspraktijken. Wat dit betreft kunnen zeker ook quota helpen meer vrouwen naar voren te brengen. Quota doorbreken taboes en motiveren: het laat zien dat vrouwen geschikt zijn voor het vak. Quota kunnen bovendien toename versnellen en houden het thema op de politieke agenda. Het invoeren van weloverwogen en specifiek geformuleerde quota op verschillende lagen en met behulp van sancties is daarom de moeite waard. Inmiddels kunnen we (verschillende vormen van) quota over de hele wereld vinden; meer dan 130 landen hebben al quota ingevoerd (Inter-Parliamentary Union, 2019). In ons essay 'De tweede sekse in politiek en openbaar bestuur: verklaringen en oplossingen voor de ondervertegenwoordiging van vrouwen' (Mügge \& Runderkamp, 2019) is een uitvoerige analyse van de voor- en nadelen van quota te vinden.

\section{Goede toerusting in het politieke ambt}

Het behoud en de doorstroom van vrouwen in de politiek is een onderwerp dat tot dusver weinig aandacht heeft gekregen in onderzoek. De minister heeft dit wel op haar radar. Om beter te anticiperen op de mogelijke uitstroom van vrouwelijke politici neemt de minister een belangrijke stap door exitonderzoek uit te laten voeren. Zo kunnen we 'afhaakmotieven, ervaren belemmeringen en ontwik- 
kel- en ondersteuningsbehoeften in het politieke ambt scherp in beeld krijgen' (Ollongren, 2019, 5). Hoe meer er bekend is over de motieven voor uitval, hoe beter gericht beleid mogelijk is. En dat is nodig (Jansen e.a., 2016).

Een concrete maatregel voor het behoud van vrouwelijke politici is de hervorming van de werkomstandigheden in parlementen en gemeenteraden. Uit andere landen zijn er voorbeelden om een parlement volledig representatief, transparant, toegankelijk en effectief te maken in al zijn functies en geledingen. De Britse hoogleraar Sarah Childs publiceerde het rapport 'The Good Parliament' op basis van haar onderzoek in Westminster (Childs, 2016). Met het rapport wil Childs bijdragen aan gelijkheid qua vertegenwoordiging, en de organisatie van het Britse parlement verbeteren. Met aanbevelingen aan commissies, de voorzitter, maar ook aan leden zelf maakt ze inzichtelijk waar barrières voor vrouwen ontstaan en hoe die verholpen kunnen worden. Childs roept bijvoorbeeld de Women in Parliament All Party Parliamentary Group op om ook hun mannelijke collega's te vragen geen panels meer te steunen die enkel uit mannen bestaan. De kunstcommissie vraagt ze om de 'ten year dead'-regel te laten varen en het zo mogelijk te maken ook portretten van belangrijke Britse vrouwen, die nu eenmaal pas later politiek actief konden worden, aan de muren van Westminster te zien hangen. Deze maatregelen tezamen kunnen het behoud van vrouwen bevorderen, omdat ze de cultuur van het parlement inclusiever maken. Het Nederlandse parlement, maar ook gemeenteraden en provinciale staten, zouden gebaat zijn met een dergelijk onderzoek.

In dit kader moet er ook aandacht zijn voor fysiek én mentaal geweld tegen vrouwelijke politici. Europees onderzoek maakte in 2018 de balans op door middel van interviews met vrouwelijke parlementariërs en hun vrouwelijke medewerkers (Inter-Parliamentary Union \& Parliamentary Assembly of the Council of Europe, 2018). Hoewel het geen representatieve steekproef betreft, laat het rapport zien dat 85 procent van de 123 geïnterviewde vrouwelijke parlementsleden tijdens hun termijn last hebben gehad van geweld, veelal online, van aanvallen van seksisme en zelfs doodsbedreigingen. Jonge vrouwelijke parlementsleden (onder de 40 jaar) hebben over het algemeen meer last van deze problemen. Dit is alarmerend, omdat dit het niet alleen lastiger maakt om vrouwen voor de politiek te behouden, maar mogelijk ook afschrikwekkend kan werken voor vrouwen die een carrière in de politiek overwegen.

De Inter-Parliamentary Union roept parlementen en raden daarom op om duidelijk(er) te communiceren wat wel en niet acceptabel gedrag is, en om ervoor te zorgen dat er goede regels zijn wat betreft het doen van (interne) aangifte (Inter-Parliamentary Union, \& Parliamentary Assembly of the Council of Europe, 2018). Ook in de Nederlandse context is het tegengaan van geweld tegen politici een prioriteit, in het verleden in het bijzonder door het programma 'Veilige Publieke Taak', dat het stellen van normen, het melden en doen van aangifte, en het leveren van nazorg als instrumenten inzet. Uit de monitor van 2018 bleek dat, hoewel het aantal fysieke bedreigingen afneemt, de online varianten groeien. Drie op de tien politieke ambtsdragers bij waterschappen, provincies en gemeenten hebben te maken gehad met geweld, een lichte stijging ten opzichte van de monitor van twee jaar daarvoor. ${ }^{6}$ Dit onderwerp missen wij tot nu toe nog 
in de Kamerbrief en de voorgestelde maatregelen, in het bijzonder voor de situatie van vrouwen.

\section{Conclusie}

Als we de democratie serieus nemen, vergt de ondervertegenwoordiging van vrouwen - in al hun diversiteit - in de politiek ook na het herdenkingsjaar van honderd jaar vrouwenkiesrecht volle aandacht. Een breed scala aan maatregelen, waarbij alle fasen van het vertegenwoordigingsproces worden betrokken, kan de instroom, het behouden en de doorstroom van vrouwen in politiek en openbaar bestuur op korte en lange termijn versterken. De Kamerbrief van minister Ollongren is daarvoor een uitstekende springplank en licht een aantal maatregelen voor elk van deze fasen uit. Ervaringen uit andere landen bieden concrete suggesties voor aanvullend beleid en onderzoek. Het is in ieders belang dat vrouwen in de Nederlandse politiek en het openbaar bestuur beter vertegenwoordigd worden én blijven.

\section{Noten}

1 Voor een uitgebreider overzicht, zie www.thoughtco.com/women-prime-ministerspresidents-20th-century-3530291.

2 De partijen die geleid werden door een vrouw zijn Partij van de Dieren (Marianne Thieme), Piratenpartij (Ancilla van de Leest) en Artikel 1 (Sylvana Simons). Voor een volledig overzicht, zie https://data.ipu.org/women-ranking.

3 De meting is in oktober 2019 verricht.

4 Voor een volledig overzicht, zie https://data.ipu.org/women-ranking? month=9\&year=2019.

5 Met ijverigheid bedoelen de auteurs bijvoorbeeld efficiënt en georganiseerd, gedisciplineerd en plichtsgetrouw, netjes en systematisch.

6 Voor het volledige rapport, zie www.rijksoverheid.nl/documenten/rapporten/ 2018/05/31/rapport-monitor-agressie-en-geweld-2018.

\section{Literatuur}

Bjarnegård, E., \& Kenny, M. (2015). Revealing the Secret Garden: The Informal Dimensions of Political Recruitment. Politics and Gender, 11(4), 748-753. https://doi.org/ 10.1017/S1743923X15000471

Cursus Politiek Actief. (n.d.). Geraadpleegd op 18 november 2019 van ProDemos website: https://prodemos.nl/samenwerking/gemeenten/burgerparticipatie/cursus-politiekactief-gemeenten-2/

Campbell, D. E., \& Wolbrecht, C. (2006). See Jane Run: Women politicians as role models for adolescents. Journal of Politics, 68(2), 233-247. https://doi.org/10.1111/j. 1468-2508.2006.00402.x

Childs, S. (2016). The Good Parliament. In University of Bristol. https://doi.org/ $10.2307 / 1857167$ 
Dynes, A. M., Hassell, H. J. G., Miles, M. R., \& Preece, J. R. (2019). Personality and Gendered Selection Processes in the Political Pipeline. Politics \& Gender, 1-21. https:// doi.org/10.1017/s1743923x19000461

I\&O Research. (2018). Monitor agressie en geweld 2018. In Ministerie van Binnenlandse Zaken. Den Haag.

Inter-Parliamentary Union. (2019). Women in Parliament in 2018: The Year in Review. Geneve.

Inter-Parliamentary Union. (2019). Percentage of women in national parliaments. Geraadpleegd op 2 november 2019, vanaf New Parline: the IPU's Open Data Platform website: https://data.ipu.org/women-ranking?month=9\&year=2019

Inter-Parliamentary Union \& Parliamentary Assembly of the Council of Europe. (2018). Sexism, harassment and violence against women in parliaments in Europe, 1-20. Geraadpleegd op www.ipu.org

Kiesraad. (2017). 28 partijen nemen deel aan Tweede Kamerverkiezing. Geraadpleegd op 1 november 2019, Kiesraad website: https://www.kiesraad.nl/actueel/nieuws/ 2017/02/03/partijen-nemen-deel-aan-tweede-kamerverkiezing-2017

Lewis, J. J. (2019). Women Prime Ministers and Presidents: 20th Century. Geraadpleegd op ThoughtCo. website: https://www.thoughtco.com/women-prime-ministerspresidents-20th-century-3530291

Mügge, L. M. (2014). Meer vrouwen in de politiek? Train studentes! Geraadpleegd op 16 september 2019, StukRoodVlees website: https://stukroodvlees.nl/meer-vrouwen-inde-politiek-train-studentes/

Mügge, L. M. (2016). Intersectionality, Recruitment and Selection: Ethnic Minority Candidates in Dutch Parties. Parliamentary Affairs, 69(3), 512-530. https://doi.org/ 10.1093/pa/gsv060

Mügge, L. M., \& Damstra, A. (2013). Gender en etniciteit in de Tweede Kamer: streefcijfers en groepsvertegenwoordiging. Res Publica, 55(3), 339-358.

Mugge, L., \& Runderkamp, Z. (2019). De tweede sekse in politiek en openbaar bestuur: Verklaringen en oplossingen voor de ondervertegenwoordiging van vrouwen.

Murray, R. (2015). What Makes a Good Politician? Reassessing the Criteria Used for Political Recruitment. Politics and Gender, 11(4), 770-776. https://doi.org/10.1017/ S1743923X15000513

Norris, P. (1996). Legislative Recruitment. In Comparing Democracies: Elections and Voting in Global Perspective. London: SAGE.

Reynolds, A. (2013). Representation and rights: The impact of LGBT legislators in comparative perspective. American Political Science Review, 107(2), 259-274. https://doi.org/ 10.1017/S0003055413000051

Ruedin, D. (2013). Why Aren't They There? Colchester: ECPR Press.

Wolbrecht, C., \& Campbell, D. E. (2007). Leading by example: female members of parliament as political role models. American Journal of Political Science, 51(4), 921-939. https://doi.org/10.1111/j.1540-5907.2007.00289.x 